\title{
Structured fiber supports for ionic liquid-phase catalysis used in gas-phase continuous hydrogenation
}

\author{
Marina Ruta ${ }^{\text {a }}$, Igor Yuranov ${ }^{\text {a }}$, Paul J. Dyson ${ }^{\mathrm{b}}$, Gabor Laurenczy ${ }^{\mathrm{b}}$, Lioubov Kiwi-Minsker ${ }^{\mathrm{a}, *}$ \\ a GGRC, ISIC, Ecole polytechnique fédérale de Lausanne (EPFL), Switzerland \\ ${ }^{\mathrm{b}}$ LCOM, ISIC, Ecole polytechnique fédérale de Lausanne (EPFL), Switzerland
}

Received 22 December 2006; revised 12 February 2007; accepted 12 February 2007

Available online 21 March 2007

\begin{abstract}
Structured supported ionic liquid-phase (SSILP) catalysis is a new concept with the advantages of ionic liquids (ILs) used as solvents for homogeneous catalyst and the further benefits of structured heterogeneous catalysts. This is achieved by confining the IL with the transition metal complex to the surface of a structured support consisting of sintered metal fibers (SMFs). In an attempt to improve the homogeneity of the IL film, the SMFs were coated by a layer of carbon nanofibers (CNFs). The IL thin film immobilized on CNF/SMF supports presents a high interface area, ensuring efficient use of the transition metal catalyst. The regular structure of the support with high porosity ( $>0.8)$ allows a low pressure drop and even gas-flow distribution in a fixed-bed reactor. The high thermoconductivity of the CNF/SMF support suppresses the formation of hot spots during exothermic hydrogenation reactions. The selective gas-phase hydrogenation of 1,3-cyclohexadiene to cyclohexene over a homogeneous Rh catalyst immobilized in IL supported on CNF/SMF was used as a test reaction to demonstrate the feasibility of the SSILP concept. The catalyst $\left[\mathrm{Rh}(\mathrm{H})_{2} \mathrm{Cl}\left(\mathrm{PPh}_{3}\right)_{3} / \mathrm{IL} / \mathrm{CNF} / \mathrm{SMF}\right]$ showed a turnover frequency of $150-250 \mathrm{~h}^{-1}$ and a selectivity of $>96 \%$. High-pressure ${ }^{1} \mathrm{H} \mathrm{NMR}$ and ${ }^{1} \mathrm{H}\left\{{ }^{31} \mathrm{P}\right\}$ NMR spectroscopy was used to provide insights into the nature of the active catalytic species.
\end{abstract}

(C) 2007 Elsevier Inc. All rights reserved.

Keywords: Ionic liquid; Structured catalyst; High-pressure NMR spectroscopy; Gas-phase hydrogenation; 1,3-Cyclohexadiene; Cyclohexene; Rh complex; Carbon nanofibers

\section{Introduction}

Supported ionic liquid-phase (SILP) catalysis has attracted increasing attention in chemical reaction engineering for applications in continuous-flow reactors [1-4]. The SILP applies a homogeneous catalyst in a layer of ionic liquid (IL) that is confined on the surface of a solid support with high specific surface area [5]. Although the resulting material is a solid, the active species in the IL phase acting as a homogeneous catalyst preserves its high selectivity. The advantage of SILP catalysis is the reduced amount of IL needed and its multiple reuses, being economically and environmentally beneficial. The feasibility of the SILP catalysis has been demonstrated by several authors on granulated silica randomly packed $[2,5]$ in fixed-bed reactors [6-8]. Moreover, most of the reactions were liquid/solid,

\footnotetext{
* Corresponding author. Fax: +41 216936190.

E-mail address: lioubov.kiwi-minsker@epfl.ch (L. Kiwi-Minsker).
}

with only few reported on the SILP catalyst applied to gasphase reactions $[6,7]$.

Catalytic beds with a regular catalyst arrangement (structured catalytic beds) present multiple advantages, including a low pressure drop during the fluid passage through the reactor and an even flow distribution, allowing a narrow residence time distribution (RTD) [9]. This property is very important for complex reactions with an intermediate as a target product. It allows for high selectivity, leading to process intensification and favorable environmental impact. The sintered metal fibers (SMFs) in the form of thin plates are used in this study as structured supports for the IL phase containing a homogeneous catalyst. The SMF plates consist of micrometer-size filaments sintered into a homogeneous 3-dimensional structure. They have a high porosity (up to 80-90\%) and high permeability, leading to a low pressure drop through the reactor bed. To increase the specific surface area (SSA) of the SMFs and to attain a homogeneous coverage by IL, the SMFs were coated by a layer of carbon 
nanofibers (CNFs). The CNF/SMF support has high thermoconductivity, suppressing hot spot formation during exothermic hydrogenation reactions [10].

The feasibility of the SSILP catalysis for gas-phase reactions is tested in the hydrogenation of 1,3-cyclohexadiene to cyclohexene as a model reaction. The reaction was carried out in a continuous fixed-bed tubular reactor with structured catalytic bed containing a homogeneous Rh-based catalyst immobilized in IL confined on CNF/SMF. To elucidate the influence of the support on catalyst activity/selectivity, the SMFs were also coated by a thin zeolite (ZSM-5) film on which the IL phase containing Rh catalyst was deposited. Catalysts were characterized by SEM and XRD, and high-pressure ${ }^{1} \mathrm{H}$ NMR and ${ }^{1} \mathrm{H}\left\{{ }^{31} \mathrm{P}\right\}$ NMR spectroscopy was used to provide insight into the nature of the active catalytic species.

\section{Experimental}

\subsection{Materials}

SMFs (Bekipor ST 20AL3; Bekaert Fiber Technology, Belgium) made of Inconel 601 (alloy composition: Ni, 58-63\%; $\mathrm{Cr}, 21-25 \% ; \mathrm{Al}, 1.4 \%$ ) in the form of panel (elementary filament diameter, $8 \mu \mathrm{m}$; panel thickness, $0.49 \mathrm{~mm}$, porosity, $81 \%$, weight, $750 \mathrm{~g} / \mathrm{m}^{2}$ ) and SMF-40 $\mu \mathrm{m}$ (Southwest Screens $\&$ Filters SA, Belgium) made of Fecralloy (alloy composition: $\mathrm{Cr}, 20 \%$; Al, 4.75\%; Y, 0.27\%; other elements, $\sim 1-2 \%$; Fe balance) in the form of a uniform pore panel (elementary filament diameter, $20 \mu \mathrm{m}$; panel thickness, $0.29 \mathrm{~mm}$; porosity, $71 \%$; weight, $675 \mathrm{~g} / \mathrm{m}^{2}$ ) were used as supports for a ionic liquid phase. Ionic liquid 1-butyl-3-methylimidazolum tetrafluoroborate, [bmim] $\left[\mathrm{BF}_{4}\right]$, and sulfonic modified 1-butyl3-methylimidazolum triflate $\left[\mathrm{bmimSO}_{3} \mathrm{H}\right]\left[\mathrm{CF}_{3} \mathrm{SO}_{3}\right]$ were synthesized in accordance with standard procedures [11]. Ionic liquid 1-butyl-3-methylimidazolum hexafluorophosphate, [bmim] [PF 6$]$ (Alfa Aesar, 99\%), other chemicals (Fluka, Aldrich, $>98 \%$ ) and gases (Carbagas, $>99.99 \%$ ) were used as received. D6 acetone (99\%) was purchased from Cambridge Isotope Laboratories. 3-(Trimethylsilyl)-1-propanesulfonic acid sodium salt (TSPSA) was purchased from Fluka and used as received.

\subsection{Synthesis of SSILP catalysts}

Before any manipulations, the SMF panels were cut into round disks $\left(12 \mathrm{~mm}\right.$ diameter) and oxidized in air at $650{ }^{\circ} \mathrm{C}$ for $3 \mathrm{~h}$ (Inconel) or at $1000^{\circ} \mathrm{C}$ for $12 \mathrm{~h}$ (Fecralloy). In Fecralloy fibers, the aluminum diffuses at high temperatures from the bulk toward the surface, generating an $\alpha-\mathrm{Al}_{2} \mathrm{O}_{3}$ layer [12].

The CNFs were grown on $\mathrm{SMF}_{\text {Inconel }}$ by decomposition of ethane in the presence of hydrogen. Details of CNF/SMF preparation have been described elsewhere [10]. Before IL deposition, the $\mathrm{CNF} / \mathrm{SMF}_{\text {Inconel }}$ were treated in an ultrasonic bath to remove nonanchored carbon $(<0.5 \mathrm{wt} \%)$. ZSM- $5 / \mathrm{SMF}_{\text {Fecralloy }}$ composite was prepared as described previously $[13,14]$.

SSILP catalysts were prepared by impregnation of the modified SMF disks with a solution containing acetone $(8 \mathrm{ml})$,
IL (1.25 g), catalyst precursor bicyclo[2.2.1]hepta-2,5-dienerhodium(I) chloride dimer, $[\mathrm{Rh}(\mathrm{nbd}) \mathrm{Cl}]_{2}(0.025 \mathrm{~g})$, triphenylphosphine, $\mathrm{PPh}_{3}$, and acid: $\mathrm{HBF}_{4}(50 \%$ aqueous solution) or $\mathrm{H}_{3} \mathrm{PO}_{4}, 0.3-0.6 \mathrm{~g}$. The $\mathrm{PPh}_{3} / \mathrm{Rh}$ molar ratio was varied from 2 to 12. After evaporation of acetone, the obtained SSILP catalysts contained $\sim 10 \mathrm{wt} \%$ of IL phase with $\sim 0.06 \mathrm{wt} \%$ of metallic Rh.

\subsection{Characterization of SSILP catalysts}

Scanning electron microscopy (SEM) was used to investigate the surface morphology of the SSILP catalysts and of the SMF supports: $\mathrm{SMF}_{\text {Inconel }}, 2 \% \mathrm{CNF} / \mathrm{SMF}_{\text {Inconel }}, \mathrm{SMF}_{\text {Fecralloy, }}$, and $6 \% \mathrm{ZSM}-5 / \mathrm{SMF}_{\text {Fecralloy. The samples were analyzed in a }}$ Philips XL30 FEG before and after IL-phase deposition. SEM micrographs at $650 \times$ and $3500 \times$ were taken with an accelerating voltage of $5-10 \mathrm{kV}$.

The specific surface areas (SSAs) of the SMF-based composites were measured using $\mathrm{N}_{2}$ adsorption-desorption at $77 \mathrm{~K}$ by a Sorptomatic 1990 instrument (Carlo Erba). The SSA was calculated by the BET method. The Dollimore/Heal model was applied to calculate the pore volume and pore size.

The X-ray diffraction (XRD) patterns of the zeolite and CNF coating were recorded by a powder diffractometer (Model D500, Siemens), using $\mathrm{Cu} K \alpha$ radiation, steps of $2 \mathrm{Q}=0.048$, and a step time of $4 \mathrm{~s}$.

NMR spectroscopy of the Rh catalyst in the IL phase was performed under oxygen-free conditions using standard Schlenk techniques with $\mathrm{N}_{2}$ protective gas. The measurements were carried out in medium-pressure sapphire NMR tubes (pressure $<120$ bar) and were followed by NMR spectroscopy. ${ }^{1} \mathrm{H},{ }^{13} \mathrm{C}$, and ${ }^{31} \mathrm{P}$ NMR spectra were recorded on a Bruker DRX 400 NMR spectrometer. TSPSA and phosphoric acid were used as references for the ${ }^{1} \mathrm{H},{ }^{13} \mathrm{C}$, and ${ }^{31} \mathrm{P}$ NMR measurements. The spectra were fitted with WINNMR, GNMR 4.0, and NMRICMA/MATLAB programs on a PC (nonlinear least squares fit to determine the spectral parameters; the differences between the measured and calculated spectra were minimized).

\subsection{Catalytic activity/selectivity testing}

Gas-phase selective hydrogenation of 1,3-cyclohexadiene to cyclohexene was carried out in a stainless steel jacketed fixedbed tubular reactor $\left(12 \mathrm{~mm}\right.$ i.d.) at $60^{\circ} \mathrm{C}$ and atmospheric pressure. Ten disks of a SSILP catalyst $\left(m_{\text {cat }} \sim 0.9 \mathrm{~g}\right)$ were placed in the middle of the reactor perpendicular to the flow. The mixture of $4 \mathrm{vol} \%$ of 1,3-cyclohexadiene, $\mathrm{C}_{6} \mathrm{H}_{8}, 20 \mathrm{vol} \%$ of $\mathrm{H}_{2}$, and $76 \mathrm{vol} \%$ of Ar (total gas flow, $50 \mathrm{ml}(\mathrm{STP}) / \mathrm{min}$ ) was used throughout the study. The gas flows were controlled by mass flow controllers. The gas lines before and after the reactor were heated $\left(\sim 90^{\circ} \mathrm{C}\right)$ to prevent condensation, and 1,3cyclohexadiene was fed into the reactor by a syringe pump. The reaction temperature was monitored by a thermocouple placed downstream on the catalytic bed.

The reaction mixture was analyzed online by gas chromatography (HP6890) using a SPB-5 capillary column and a flame ionization detector. Catalyst performance was monitored for 


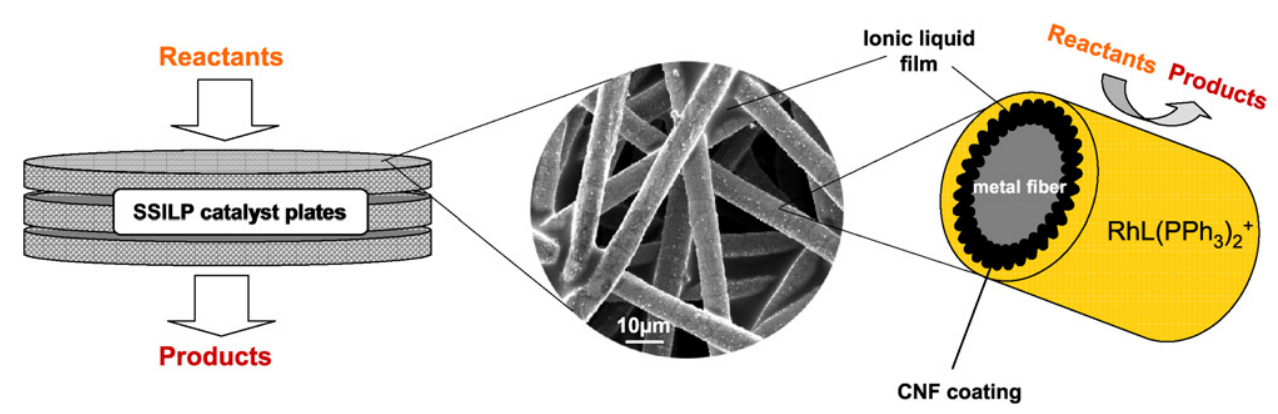

Fig. 1. Schematic presentation of structured SMF support applied for ionic liquid-phase catalysis during gas-phase hydrogenation.

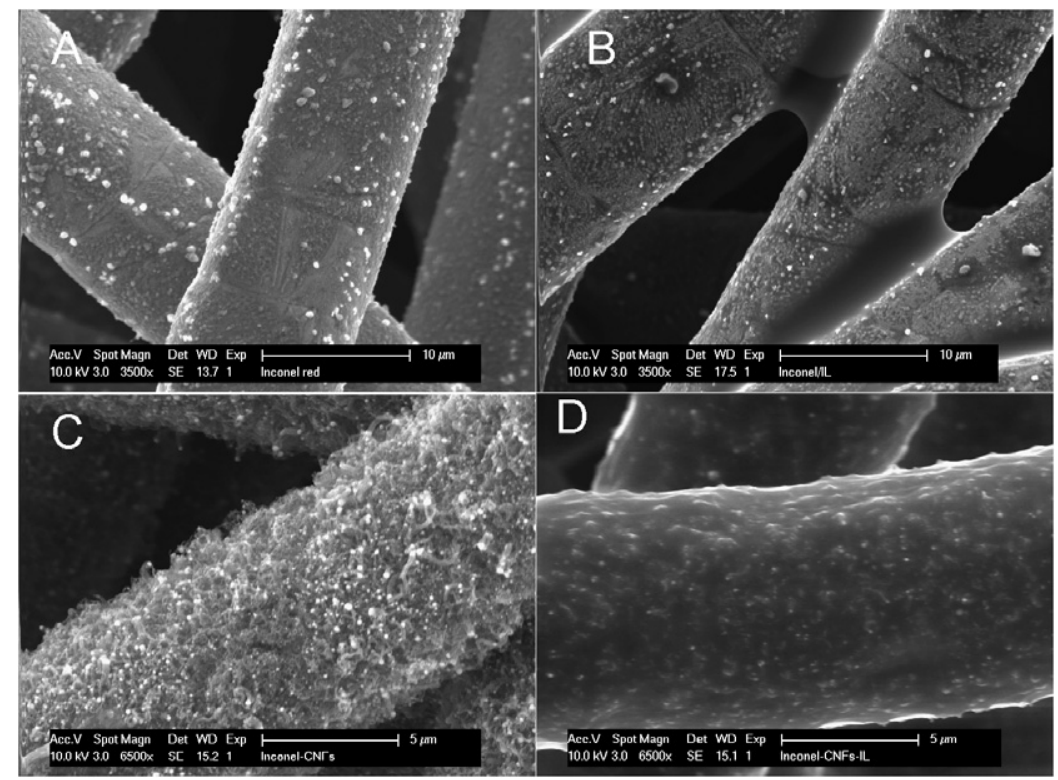

Fig. 2. SEM images of SMF Inconel: (A) SMF oxidized; (B) IL/SMF; (C) CNF/SMF; (D) IL/CNF/SMF

$5 \mathrm{~h}$ on stream. The conversion of 1,3-cyclohexadiene was calculated from the difference between its reactor inlet and outlet concentrations. The reaction selectivity toward cyclohexene was calculated as the molar ratio of cyclohexene obtained to 1,3-cyclohexadiene converted. Catalytic activity was expressed in terms of specific reaction rate $\left(R, \mathrm{~h}^{-1}\right)$, calculated as the reaction rate (mol of cyclohexadiene converted per $\mathrm{h}$ ) over the mol of Rh. Steady-state catalytic activity was reached after $3 \mathrm{~h}$ on stream, and thus the corresponding values of $R$ were used for characterization. When the kinetics of the reaction was not influenced by mass transport, the specific reaction rate was considered the catalyst turnover frequency (TOF).

\section{Results and discussion}

\subsection{Catalyst characterization}

The SMF plates consist of uniform metallic filaments sintered into a homogeneous 3-dimensional structure with porosity of up to 80-90\% with high permeability. The fibrous matrix exhibits high mechanical strength combined with chemical and thermal stability. It also acts as a static micromixer to prevent gas channeling within the catalytic bed. Due to their small fiber diameter $(\sim 2-20 \mu \mathrm{m})$, SMFs have a relatively large specific surface area, being suitable supports for micrometer-thickness films of a catalytically active phase [14]. This catalyst design decreases internal diffusion limitations, reducing the amount of catalyst required. High thermal conductivity of the metal SMF provides a radial heat transfer twice that of randomly packed catalytic beds [15], leading to nearly isothermal conditions during exothermic reaction operation. Fig. 1 shows a schematic representation of the structured SMF support in application to ILP catalysis during gas-phase hydrogenation. The SMFs can be used as is, or their surfaces can be modified to improve the homogeneous spreading of IL.

In this study, different modified SMFs were used for ILphase deposition, and their surface morphologies were characterized by SEM. The SEM images with different magnifications are shown in Figs. 2 and 3. As can be seen, the SMF Inconel panels consist of uniform metal fibers $8 \mu \mathrm{m}$ in diameter, whereas

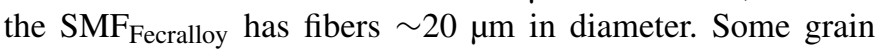
boundaries can be seen on the metal surface, indicating the formation of metal oxides after SMF oxidation (Figs. 2A and $3 \mathrm{~A})$. The surface roughness is much greater for $\mathrm{SMF}_{\mathrm{Fecralloy}}$ (Fig. 3A), due to an $\alpha-\mathrm{Al}_{2} \mathrm{O}_{3}$ layer of Fecralloy fibers formed during the high-temperature treatment; aluminum diffuses from the bulk toward the surface, where it is oxidized, generating oxide film [12]. The filters present an open macrostructure with 


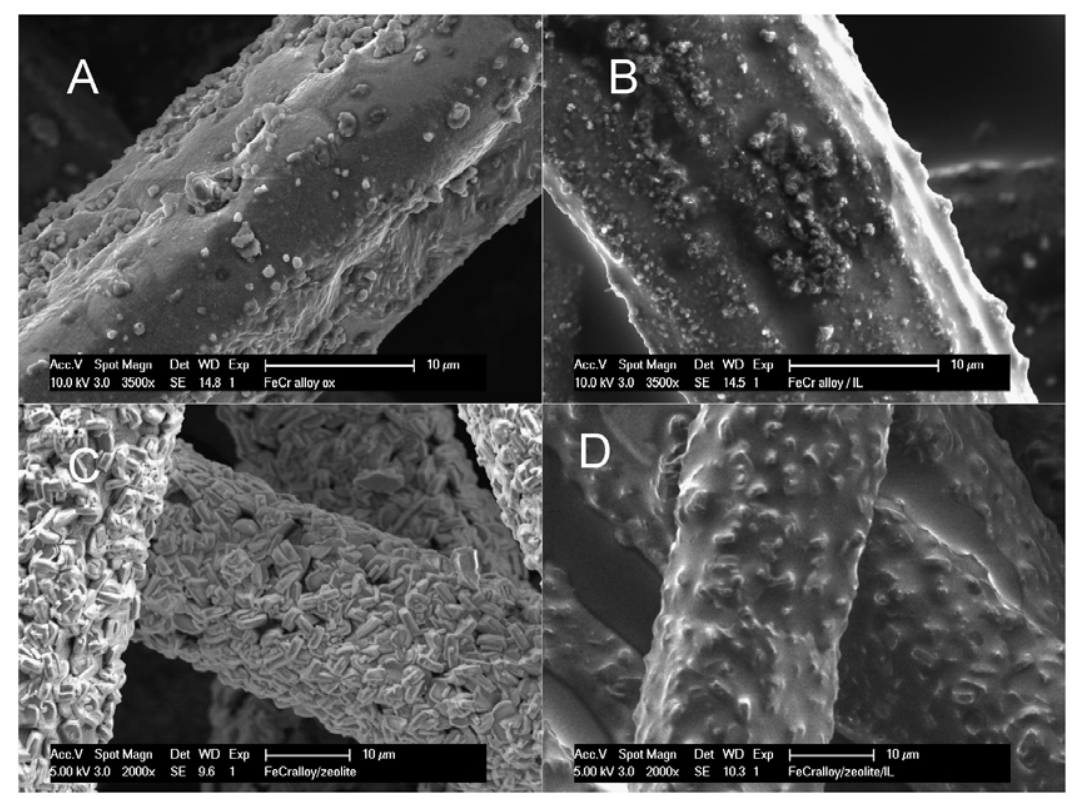

Fig. 3. SEM images of SMFFecralloy: (A) SMF oxidized; (B) IL/SMF; (C) ZSM-5/SMF; (D) ZSM-5/SMF/IL.

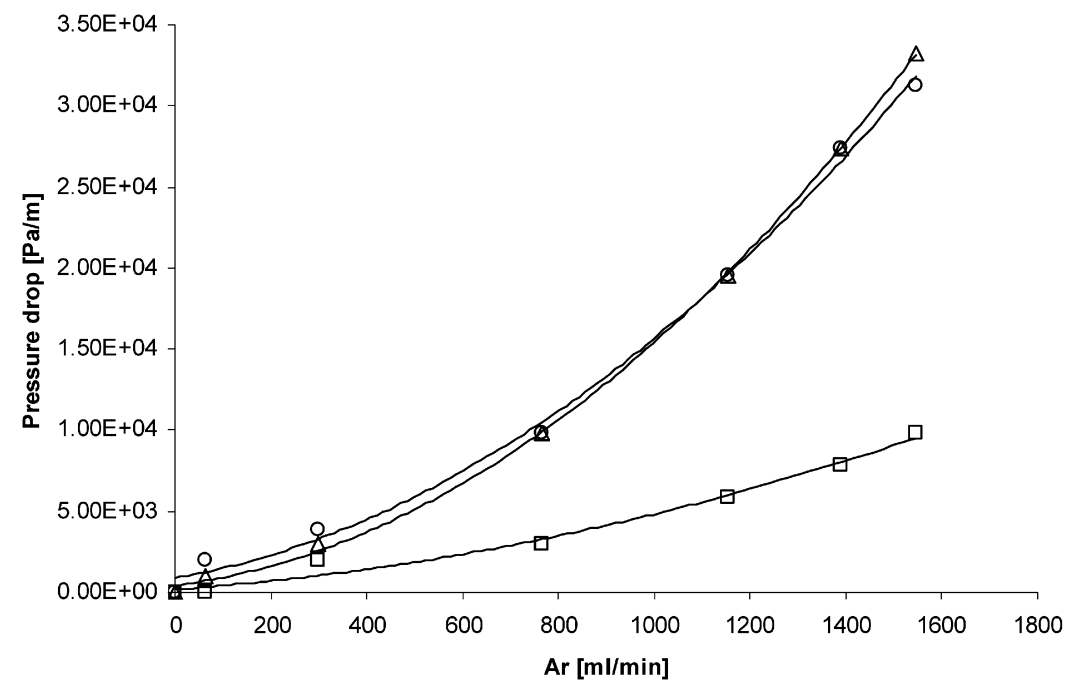

Fig. 4. Pressure drop as a function of inlet gas flow rate: $(\square)$ empty reactor, $(\triangle) \mathrm{SMF}_{\text {Inconel }},(\bigcirc) \mathrm{IL} / \mathrm{SMF}_{\text {Inconel }}$.

high porosity even after the coating of their surface by CNFs (Fig. 2C) or zeolites (Fig. 3C). As seen on the images of the supports and related SSILP catalysts (Figs. 2 and 3), the liquid phase completely covers the metal fibers. However, the homogeneity of the coverage depends strongly on the fiber surface morphology. On relatively smooth Inconel fibers (Fig. 2A), an excess of IL tends to form meniscuses at fiber crossing points (Fig. 2B), whereas the mesoporous layer of CNF on the metal surface (Fig. 2C) allows easy spreading, leading to uniform IL films (Fig. 2D). The same phenomenon is observed when analyzing $\mathrm{SMF}_{\text {Fecralloy }}$ and ZSM-5/SMF Fecralloy (Fig. 3). Zeolites on Fecralloy fibers form a network in which ionic liquid can be easily deposited, resulting in a uniform film (Fig. 3D).

Fig. 4 demonstrates that IL ( $10 \mathrm{wt} \%$ ) supported on SMF does not affect gas permeability compared with the support itself. The pressure drop in the reactor remains almost the same after IL deposition on $\mathrm{SMF}_{\text {Inconel }}$.

\subsection{Catalyst activity/selectivity}

Catalyst stability is presented in Fig. 5, where the concentration and selectivity to cyclohexene is plotted as a function of time on stream for $\mathrm{SMF}_{\text {Inconel }}$ support with the catalyst $[\mathrm{Rh}(\mathrm{nbd}) \mathrm{Cl}]_{2}+\mathrm{PPh}_{3} /[\mathrm{bmim}]\left[\mathrm{BF}_{4}\right] / \mathrm{HBF}_{4}$ (Rh loading $0.06 \%$, $\mathrm{PPh}_{3} / \mathrm{Rh}$ ratio $8, \mathrm{HBF}_{4} /[\mathrm{bmim}]\left[\mathrm{BF}_{4}\right]$ ratio 0.5$)$. The supported catalyst shows suitable stability during continuous operation along with the high selectivity to cyclohexene. High selectivity to cyclohexene was previously reported by Chauvin et al. [16], explained by the lower solubility of cyclohexane compared with 1,3-cyclohexadiene and cyclohexane in IL, which allows cyclohexene to escape from the IL phase before being hydrogenated to cyclohexane.

As can be seen in Fig. 5, the catalyst attains a quasi-steadystate after $\sim 3 \mathrm{~h}$ on stream; thus, the reaction rates could be used to compare the efficiencies of different catalytic systems. 


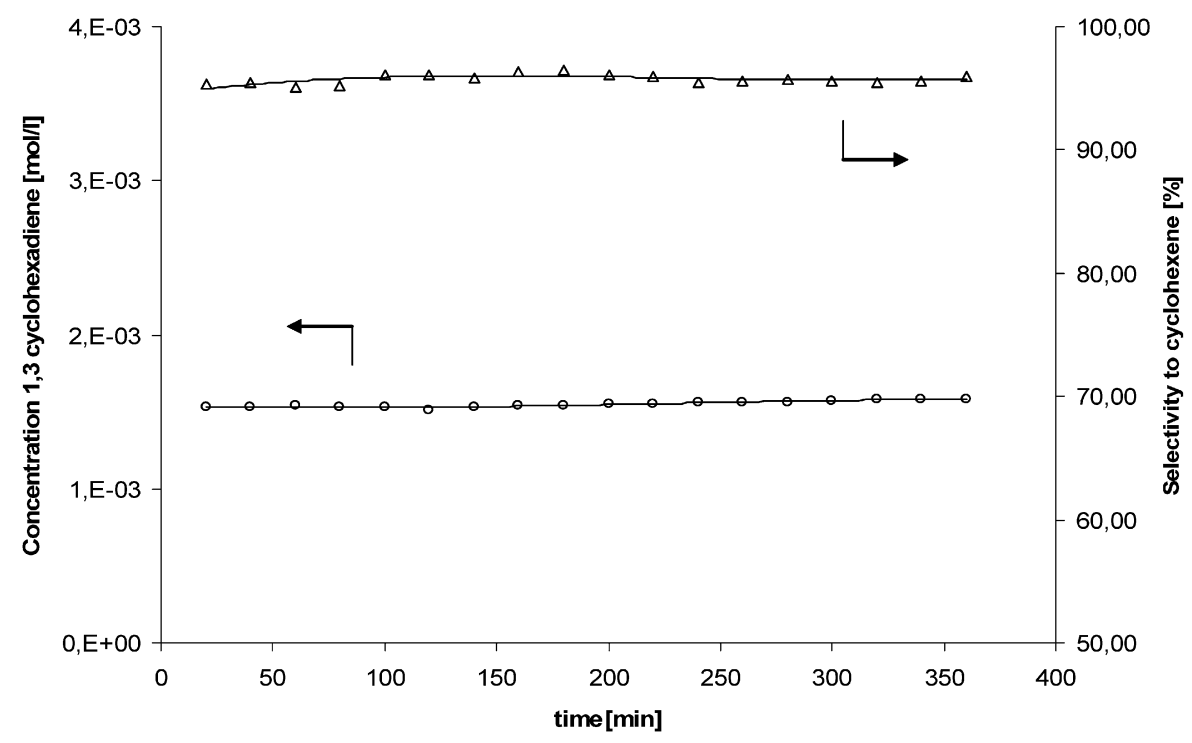

Fig. 5. Concentration of 1,3-cyclohexadiene $(O)$ and selectivity to cyclohexene $(\triangle)$ as functions of time on stream. Catalyst: $\left[\mathrm{Rh}(\mathrm{nbd}) \mathrm{Cl}_{2}+\mathrm{PPh}_{3} / \mathrm{bmimBF}{ }_{4} / \mathrm{HBF}_{4}\right.$ $\left(\mathrm{Rh} 0.06 \%, \mathrm{PPh}_{3} / \mathrm{Rh}\right.$ ratio $\left.8, \mathrm{HBF}_{4} /[\mathrm{bmim}]\left[\mathrm{BF}_{4}\right]=0.5\right)$ supported on $\mathrm{SMF}_{\text {Inconel }}$.

Table 1

$\left[\mathrm{Rh}(\mathrm{nbd})\left(\mathrm{PPh}_{3}\right)_{2}\right]^{+}$-based SSILP catalysts for 1,3-cyclohexadiene hydrogenation

\begin{tabular}{|c|c|c|c|c|c|c|c|c|}
\hline Entry & Support (SMF) & {$[\mathrm{bmim}][\mathrm{X}]$} & $\begin{array}{l}\text { IL loading } \\
(\%)\end{array}$ & $\begin{array}{l}\text { Rh loading } \\
(\%)\end{array}$ & Acid/IL ratio & $\begin{array}{l}\mathrm{PPh}_{3} / \mathrm{Rh} \\
\text { ratio, } r\end{array}$ & $R\left(\mathrm{~h}^{-1}\right)$ & $S(\%)$ \\
\hline 1 & Inconel & $\mathrm{PF}_{6}$ & 10 & 0.06 & - & 8 & $<1$ & - \\
\hline 2 & Inconel & $\mathrm{PF}_{6}$ & 10 & 0.06 & $0.3\left(\mathrm{H}_{3} \mathrm{PO}_{4}\right)$ & 8 & 20 & 93 \\
\hline 4 & Inconel & $\mathrm{PF}_{6}$ & 11 & 0.06 & $1.0\left(\mathrm{H}_{3} \mathrm{PO}_{4}\right)$ & 8 & 35 & 96 \\
\hline 5 & $2 \% \mathrm{CNF} /$ Inconel & $\mathrm{PF}_{6}$ & 11 & 0.06 & $0.5\left(\mathrm{H}_{3} \mathrm{PO}_{4}\right)$ & 8 & 140 & $>96$ \\
\hline 8 & Inconel & $\mathrm{BF}_{4}$ & 11 & 0.06 & $0.5\left(\mathrm{HBF}_{4}\right)$ & 6 & 150 & 90 \\
\hline 9 & Inconel & $\mathrm{BF}_{4}$ & 11 & 0.06 & $0.5\left(\mathrm{HBF}_{4}\right)$ & 8 & 130 & 96 \\
\hline 10 & $2 \% \mathrm{CNF} /$ Inconel & $\mathrm{BF}_{4}$ & 12 & 0.06 & $0.5\left(\mathrm{HBF}_{4}\right)$ & 8 & 285 & $>96$ \\
\hline 11 & Fecralloy & $\mathrm{PF}_{6}$ & 8 & 0.06 & $0.5\left(\mathrm{H}_{3} \mathrm{PO}_{4}\right)$ & 8 & 55 & 95 \\
\hline 12 & $6 \%$ ZSM-5/Fecr. & $\mathrm{PF}_{6}$ & 7 & 0.06 & $0.5\left(\mathrm{H}_{3} \mathrm{PO}_{4}\right)$ & 8 & 115 & 95 \\
\hline
\end{tabular}

Table 1 presents the values for catalyst activity and selectivity with varying parameters: SMF support and IL used, acid/IL and $\mathrm{PPh}_{3} / \mathrm{Rh}$ molar ratios, and $\mathrm{Rh}$ loading (wt\%).

All of the Rh-based SSILP catalysts were found to be active in the gas-phase hydrogenation of 1,3-cyclohexadiene only in the presence of acid. When an acid was added to the solution, the resulted catalyst was able to reach the specific reaction rate of $140 \mathrm{~h}^{-1}$ (entry 5) for $[\mathrm{bmim}]\left[\mathrm{PF}_{6}\right] / \mathrm{H}_{3} \mathrm{PO}_{4}$. When $[\mathrm{bmim}]\left[\mathrm{BF}_{4}\right] / \mathrm{HBF}_{4}$ was used, the observed reaction rate increased up to $285 \mathrm{~h}^{-1}$ (entry 10). On changing the molar ratio of acid/IL for $[\mathrm{bmim}]\left[\mathrm{PF}_{6}\right] / \mathrm{H}_{3} \mathrm{PO}_{4}$ (entries $1,2,3$, and 4 ), an optimal ratio of 0.5 was found. The same ratio was then used for the $[\mathrm{bmim}]\left[\mathrm{BF}_{4}\right] / \mathrm{HBF}_{4}$ catalytic system; catalyst activity was higher for $[\mathrm{bmim}]\left[\mathrm{BF}_{4}\right] / \mathrm{HBF}_{4}$ compared with $[$ bmim $]\left[\mathrm{PF}_{6}\right] / \mathrm{H}_{3} \mathrm{PO}_{4}$ (entries 4, 9 and 5, 10).

The observation that an excess of $\left[\mathrm{H}^{+}\right]$activates the catalyst suggests the nature of the active species in diene hydrogenation. Osborn reported that the $\mathrm{Rh}^{+}$active center coordinates molecular hydrogen, giving catalytically active species [17], as described by the following equilibrium:

$\left[\mathrm{Rh}(\mathrm{H})_{2} \mathrm{~L}_{n}\right]^{+} \rightleftarrows \mathrm{RhHL}_{n}+\mathrm{H}^{+}$.

In an excess of $\left[\mathrm{H}^{+}\right]$, this equilibrium is shifted to the left, suggesting that the cationic dihydride is the active species, whereas the monohydride species gives poor catalytic activity.

To verify this, a sulfonic acid functionalized IL, [bmim$\left.\mathrm{SO}_{3} \mathrm{H}\right]\left[\mathrm{CF}_{3} \mathrm{SO}_{3}\right]$, was used as a solvent for the $\mathrm{Rh}$ complex. It appeared that even without the addition of an acid, the catalyst was active and selective toward cyclohexene formation (entry 13).

Catalyst performance was found to depend also on the presence of $\mathrm{PPh}_{3}$ in the catalytic phase. The bottom part of Table 1 presents catalyst activity and selectivity values for various $\mathrm{PPh}_{3} / \mathrm{Rh}$ molar ratios. As seen, with a stoichiometric ratio, low activity and selectivity were observed (entry 6). Improved performance was achieved for $\mathrm{PPh}_{3} / \mathrm{Rh}$ ratios between 4 and 8 . 


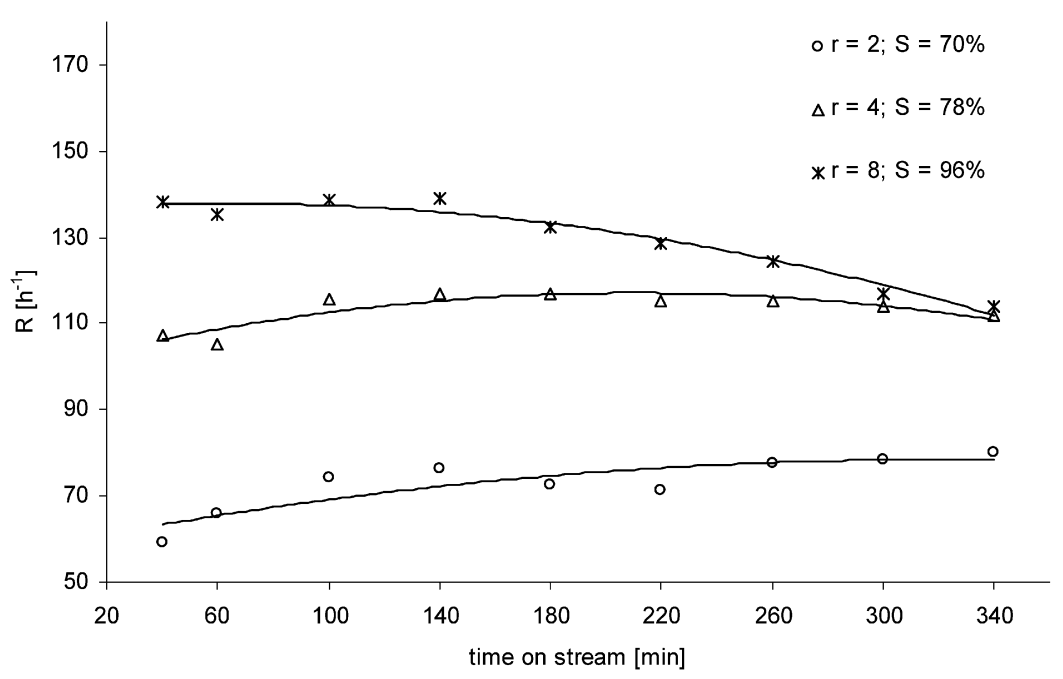

Fig. 6. Dependence of the specific reaction rate $R\left(\mathrm{~h}^{-1}\right)$ on the $\mathrm{PPh}_{3} / \mathrm{Rh}$ ratio, $r$. Catalyst: $[\mathrm{Rh}(\mathrm{nbd}) \mathrm{Cl}]_{2}+\mathrm{PPh}_{3} / \mathrm{bmimBF}_{4} / \mathrm{HBF}_{4}\left(\mathrm{Rh}_{0.06} \mathrm{wt} \%\right.$, $\mathrm{HBF}_{4} /$ $[$ bmim $]\left[\mathrm{BF}_{4}\right]$ ratio 0.5$)$ supported on $\mathrm{SMF}_{\text {Inconel }}$.

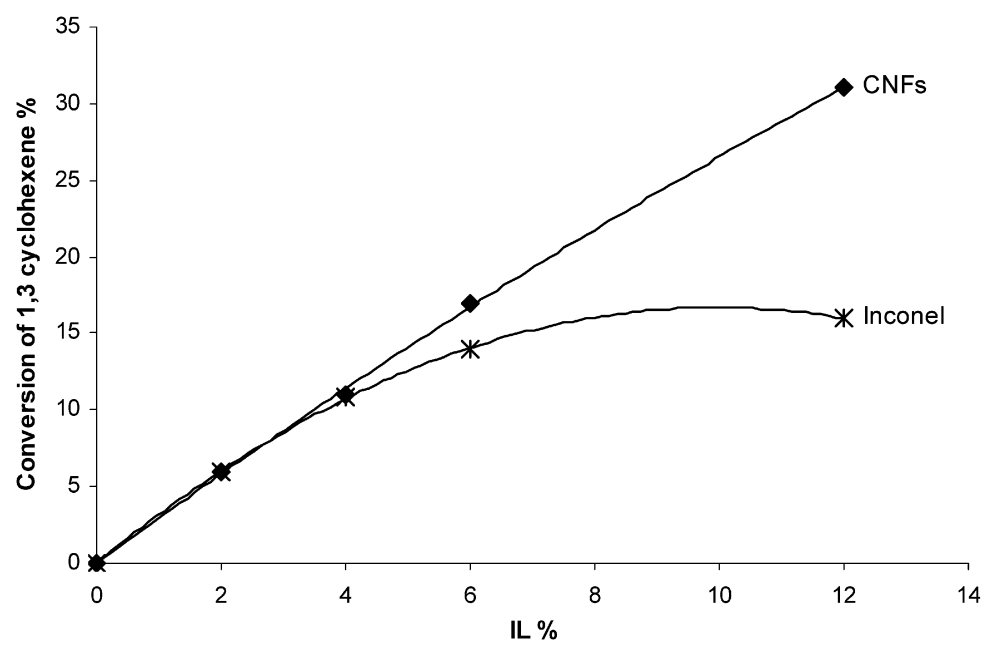

Fig. 7. Conversion of 1,3-cyclohexadiene as a function of the loading of IL plus the Rh catalyst ( $0.9 \mathrm{wt} \% \mathrm{Rh}$ in $\left.\mathrm{IL}, \mathrm{PPh}_{3} / \mathrm{Rh}^{\mathrm{ratio}} 8, \mathrm{HBF}_{4} /[\mathrm{bmim}][\mathrm{BF} 4] \mathrm{ratio} 0.5\right)$ on the supports $\mathrm{CNF} / \mathrm{SMF}$ Inconel and $\mathrm{SMF}_{\text {Inconel }}$.

For a $\mathrm{PPh}_{3} / \mathrm{Rh}$ ratio of 8 , suitable activity and high selectivity (entries 9 and 10) were attained, comparable to the selectivity observed for this catalyst in nonsupported IL [19].

The effect of the $\mathrm{PPh}_{3} / \mathrm{Rh}$ ratio is shown in Fig. 6. The donor character of the phosphine ligands under a hydrogen atmosphere enhances the yield of dihydride species [18]. This observation agrees with the suggested dihydride species [Eq. (1)] active for the diene hydrogenation. A similar dependence of Rh-based SILP catalyst activity on the biphosphine ligand (sulfoxantphos) concentration was recently reported for continuous fixed-bed gas-phase hydroformylation of propene [8]; the authors attributed the observed effect to an irreversible interaction of the ligand with acidic silanol groups on the silica surface.

Table 1 also shows that catalyst activity depends on the support used. The reason could be linked to the chemical nature and/or morphology of the support. The latter parameter is known to control the wetting properties of IL, influencing the thickness of the catalytic-phase film. Thin films spread over high-surface-area supports should preclude diffusion lim- itations, increasing the overall reaction rate. To verify whether the reaction kinetics are influenced by diffusion, several catalysts with different IL loadings (2-12 wt\%) and the same $\mathrm{Rh}$ in IL $(0.9 \mathrm{wt} \%)$ were synthesized. The results, presented in Fig. 7, show that the activity of the catalysts supported on $\mathrm{CNF} / \mathrm{SMF}_{\text {Inconel }}$ is directly proportional to the catalyst loading up to $12 \mathrm{wt} \%$. This indicates that the reaction is not affected by gas diffusion through the IL film. However, the catalysts supported on $\mathrm{SMF}_{\text {Inconel }}$ indicate the influence of diffusion for IL phase loading $>4 \mathrm{wt} \%$. These results explain the observed difference in activity and its dependence on the SMF support. As seen from the results presented in Table 1, for the same catalysts supported on $\mathrm{SMF}_{\text {Inconel, }}$, the specific reaction rate is always lower than that of the $\mathrm{CNF} / \mathrm{SMF}_{\text {Inconel }}$ support (entries 3,5 and $9,10)$. The same phenomenon is observed for $\mathrm{SMF}_{\text {Fecralloy }}$ support compared to ZSM-5/SMF Fecralloy (entries 11 and 12). The latter support demonstrated higher activity, which also could be due to the formation of a thin homogeneous IL film detected by SEM, as on the CNF/SMF Inconel support. The thinness of 


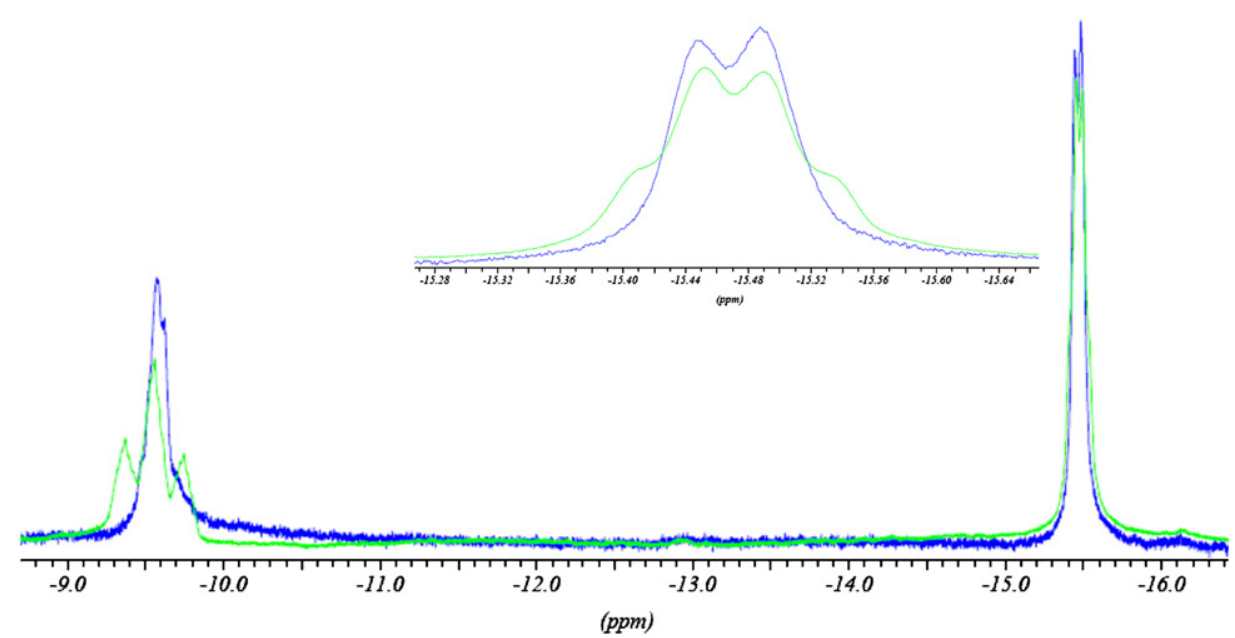

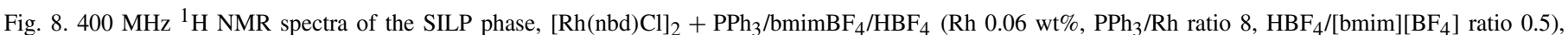
in acetone- $d_{6}$ under 100 bar $\mathrm{H}_{2}$; green, ${ }^{1} \mathrm{H}$ NMR spectrum; blue, ${ }^{1} \mathrm{H}\left\{{ }^{31} \mathrm{P}\right\}$ NMR spectrum. For clarity, the peak at -15.5 ppm has been enlarged (insert). (For interpretation of the references to color in this figure, the reader is referred to the web version of this article.)

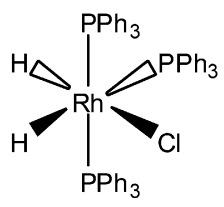

$$
\begin{gathered}
\text { A, species observed } \\
\text { in situ by NMR } \\
\text { spectroscopy }
\end{gathered}
$$

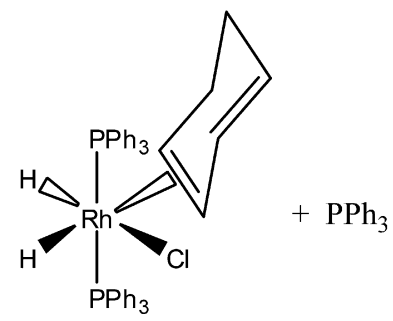

B, proposed catalytic intermediate

Scheme 1. Proposed catalytically active rhodium species for the selective hydrogenation of 1,3-cyclohexadiene.

the IL layer decreases the influence of mass transfer. Nevertheless, the same catalyst on a $\mathrm{CNF} / \mathrm{SMF}_{\text {Inconel }}$ support (entry 5) provides higher activity and selectivity compared with ZSM$5 / \mathrm{SMF}_{\text {Fecralloy }}$ (entry 12 ), demonstrating the effect of the support surface on the Rh catalyst activity. The chemical inertness of the CNF prevents the interaction between the support and the active species dissolved in IL. At the same time, the surface acid groups of the zeolite coating could interact with the phosphine ligands, affecting the activity/selectivity of the catalytic system [8].

\subsection{NMR studies}

High-pressure NMR spectroscopy was used to identify the nature of the catalytically active rhodium species present in the SSILP under hydrogen at 100 bar. The ${ }^{1} \mathrm{H}$ NMR spectrum (Fig. 8) exhibits a triplet at $-9.6 \mathrm{ppm}$ and a quartet at $-15.5 \mathrm{ppm}$, which corresponds to $\mathrm{Rh}(\mathrm{H})_{2} \mathrm{Cl}\left(\mathrm{PPh}_{3}\right)_{3}$ (presented as $\mathbf{A}$ in Scheme 1), in agreement with literature data [20]. However, the coupling of the triplet is reduced in our experiment due to the presence of excess $\mathrm{PPh}_{3}$, which is in rapid exchange with the $\mathrm{PPh}_{3}$ ligand trans to the hydride. The structure of $\mathbf{A}$ was further verified by ${ }^{1} \mathrm{H}\left\{{ }^{31} \mathrm{P}\right\}$ NMR spectroscopy. It is reasonable to assume that the $\mathrm{PPh}_{3}$ ligand trans to the hydride that is in rapid exchange is replaced by the cyclohexadiene substrate, and thus $\mathbf{B}$ in the scheme is the probable reaction intermediate. In the absence of acid, the catalyst rapidly decomposes, giving metallic rhodium. This may explain the occurrence of catalyst deactivation without the addition of acid to the catalytic system.

\section{Conclusions}

Based on our findings, we can state the following conclusions of this study:

1. An SSILP Rh-based catalyst was shown to be active in the gas-phase hydrogenation of 1,3-cyclohexadiene with a high selectivity to cyclohexene ( $>96 \%$ ). SMF plates with high porosity were used as structured supports.

2. Excess phosphine ligand and acid in the IL phase are required to maintain catalyst activity and selectivity.

3. The catalytic species active in the studied reaction is suggested to be $\mathrm{Rh}(\mathrm{H})_{2} \mathrm{Cl}\left(\mathrm{PPh}_{3}\right)_{3}$, as follows from the highpressure ${ }^{1} \mathrm{H}$ NMR and ${ }^{1} \mathrm{H}\left\{{ }^{31} \mathrm{P}\right\}$ NMR spectroscopy results.

4. In an effort to improve the homogeneity of IL film, the SMF supports were coated with a layer of CNFs. The IL thin film immobilized on $\mathrm{CNF} / \mathrm{SMF}_{\text {Inconel }}$ support with high thermal conductivity and large interface area ensures efficient use 
of the transition metal catalyst without mass-transfer limitations and isothermal conditions during the exothermic reaction.

5. The SSILP catalyst, $\left[\mathrm{Rh}(\mathrm{H})_{2} \mathrm{Cl}\left(\mathrm{PPh}_{3}\right)_{3} / \mathrm{IL} / \mathrm{CNF} / \mathrm{SMF}\right]$, showed high selectivity $(>96 \%)$ and turnover frequency up to $250 \mathrm{~h}^{-1}$ with acceptable stability during $6 \mathrm{~h}$ on stream.

\section{Acknowledgments}

The authors thank Professor Simon Duckett (York, UK) for helpful discussions. Financial support was provided by the Swiss National Science Foundation.

\section{References}

[1] M.H. Valkenberg, C. de Castro, W.F. Holderich, Appl. Catal. A Gen. 215 (2001) 185.

[2] M.H. Valkenberg, C. de Castro, W.F. Holderich, Green Chem. 4 (2002) 88.

[3] C.P. Mehnert, R.A. Cook, N.C. Dispenziere, M. Afeworki, J. Am. Chem. Soc. 124 (2002) 12932.

[4] C.P. Mehnert, E.J. Mozeleski, R.A. Cook, Chem. Commun. (2002) 3010.
[5] C.P. Mehnert, Chem. Eur. J. 11 (2004) 50.

[6] A. Riisager, K.M. Eriksen, P. Wasserscheid, R. Fehrmann, Catal. Lett. 90 (2003) 149

[7] A. Riisager, P. Wasserscheid, R. van Hal, R. Fehrmann, J. Catal. 219 (2003) 452.

[8] A. Riisager, R. Fehrmann, S. Flicker, R. van Hal, M. Haumann, P. Wasserscheid, Angew. Chem. Int. Ed. 44 (2005) 815.

[9] A. Cybulski, J.E. Moulijin, Structured Catalysts and Reactors, Marcel Dekker, New York, 1998.

[10] P. Tribolet, L. Kiwi-Minsker, Catal. Today 102 (2005) 15.

[11] D. Zim, R.F. de Souza, J. Dupont, A.L. Monteiro, Tetrahedron Lett. 39 (1998) 7071.

[12] C. Badini, F. Laurella, Surf. Coat. Technol. 135 (2001) 291.

[13] I. Yuranov, L. Kiwi-Minsker, A. Renken, Appl. Catal. B Environ. 43 (2003) 217.

[14] I. Yuranov, A. Renken, L. Kiwi-Minsker, Appl. Catal. A Gen. 281 (2005) 55.

[15] D.R. Cahela, B.J. Tatarchuk, Catal. Today 69 (2001) 33.

[16] Y. Chauvin, Act. Chim. (1996) 44.

[17] R.R. Schrock, J.A. Osborn, J. Am. Chem. Soc. 98 (1976) 2134.

[18] R.H. Pignolet, Homogeneous Catalysis with Metal Phosphine Complexes, Plenum Press, New York, 1983.

[19] Y. Chauvin, L. Mussmann, H. Olivier, Angew. Chem. Int. Ed. Engl. 34 (1996) 2698

[20] S.B. Duckett, C.L. Newell, R. Eisenberg, J. Am. Chem. Soc. 116 (1994) 10548. 